\title{
Primera Convención Nacional de Obstetricia y Ginecología - Bogotá, 1953
}

La Comisión encargada de elaborar las conclusiones finales de la Convención, compuesta por los doctores Rafael Peralta C., Eduardo Acosta Bendeck, Bernardo Botero Peláez, Tomás Becerra, Pedro Nel Cardona, Primitivo Rey Rey y Hernando Amaya León, ha rendido el siguiente informe:

\section{CONCLUSIONES}

La Primera Convención Nacional de Obstetricia y Cinecología desarrollí un amplio programa científico y concluiremos sobre los temas de éste y sobre otros aspectos.

\section{a) TEMAS OBSTETRICOS.}

10-Toxicosis GRavídicas.-Todavía es delicada la toxicosis gravídica por razones etiológicas y por los indices de mortalidad materna y fetal; al mismo tiempo que persiste el desacuerdo terapéutico, ya que hay controversia entre los tratamientos médico puro y obstétrico puro. En tal sentido, las conductas deben tener la mira de salvar las dos vidas hasta donde sea posible, y debe inten. sificarse el tratamiento profiláctico en consultas prenatales bien organizadas.

20-Factor Rh.-La Convención considera: Que es imprescindible la determinación del factor $R h$ siempre que se vaya a administrar sangre a una mujer a fin de asegurar que ésta sea compatible para evitar los graves inconvenientes de la inmunización anti-Rh.

Que es indispensable la determinación del factor Rh en toda gestante, así como el control de aglutininas anti-Rh en las gestantes $R h$ negativas con esposo Rh positivo, a fin de estar prevenidos para adoptar una conducta apropiada.

Que es indispensable el control clinico y hematológico de todo niño hijo de madre Rh negativa, aun en ausencia de isoinmunización demostrable en ésta.

Que aunque hasta el presente se ha laborado con la conducta consistente en la inducción del parto prematuro, la opinión, así extranjera como nacional, más aceptada hoy, es la de procurar los partos a término de las gestantes $P h$. negativas. 
Se desaconseja la vía del seno longitudinal superior para practicar trans. fusiones a los recién nacidos.

30-Temas libres.-Merecieron interés y es recomendable seguir su estudio, los siguientes: a) Nueva técnica de embriotomía con el aparato de Turpin; b) los procedimientos de pelmivetría en radiodiagnóstico obstétrico y el interés de su divulgación; c) la maniobra de Ramírez Merchán para la aplicación de forceps en variedades transversas y posteriores de vértice; d) la mortalidad materna en clínicas obstétricas: es todavía alarmante el índice hospitalario de Bogotá, como es lujoso el de clínicas diferentes y no es escasa la incidencia de las toxicosis. Si en el primero, además del estado precario del elemento paciente, hay factores de organización interna determinantes, sería necesario revisarlos. e) El concepto del encajamiento, tendiente a demostrar que es precoz en la primigestante como excepción pero no como regla.

\section{b) TEMAS GINECOLOGICOS.}

19-Endometritis.-Apenas se esbozó este tema, a pesar de haber sido oficialmente señalado, en dos trabajos, y necesita nuevos estudios especialmente desde el punto de vista histopatológico, por lo cual podría recomendarse como tema para futuras convenciones.

$2^{\circ}$-Esterilidad.-Es un problema de trascendencia en ginecología y de novedad entre nosotros. Apenas se inicia la consulta de esterilidad en Bogotá, Medellin y Bucaramanga y es de desear que los demás centros ginecológicos sigan el mismo derrotero. Debe imponerse como condición para iniciar el estudio de la pareja estéril, el examen primero del marido a fin de evitar inútiles erogaciones en tiempo y dinero, por la resistencia del varón.

\section{c) CONCLUSIONES VARIAS.}

10--Las Clinicas obstétricas y Hospitales necesitan mejorar sus sistemas estadísticos de acuerdo con las normas internacionales $y$ deben ser dirigidas estas instituciones, amplia y científicamente, por especialistas en esta rama médica.

29-Próxima Convención.-Debe reunirse dentro de dos años y en cuanto " sede de ella recomendamos estudiar un acuerdo de las directivas de la Sociedad Colombiana de Obstetricia y Ginecología con el Colegio Nacional de Cirujanos, que ha fijado como sede de su Tercera Convención a la ciudad de Cali.

30-Temas para la próxima Convención.-a) Temas (rinecológicos: CANCER DEL CUELLO UTERINO $y$ TEMAS LIBRES. b) Temas Obstétricos: FACTOR Rh, SHOCK OBSTETRICO $y$ TEMAS LIBRES.

$4^{0}$-Los obstetras y ginecólogos han trabajado científica y desinteresada mente por el progreso de sus especialidades en Colombia $y$ en este sentido el balance final es favorable. 
La Redacción de la Revista recomienda a todos los especialistas del país, un atento estudio de las conclusiones de la Primera Convención Nacional de Obstetricia y Ginecología, no por simple información sino con ánimo de que lleven a la práctica los diferentes puntos acordados, con la seguridad de que ello redundará en beneficio de las pacientes y en progreso de nuestra especiat lidal.

\section{COMITE NACIONAL DE REDACCION DE LA REVISTA}

Con motivo de la Primera Convención de Obstetricia y Ginecología, el Presidente de la Sociedad y los Directores de la Revista nombraron un Comité Nacional de Redacción integrado por representantes de todos los departamentos del país. En esta forma la Sociedad y la Revista, reafirmaron su carúcter nacional y manifestaron una vez más el deseo de conseguir colaboración y sostener vínculos científicos y gremiales con todos los especialistas colombianos.

Como se verá en la Sección de Correspondencia, varios colegas han contestado manifestando su aceptación del cargo y ofreciendo ampliamente mamtener y fortalecer dichos nexos.

$$
* * *
$$

\section{MEMORIAS DE LA PRIMERA CONVENCION NACIONAI. DE OBSTETRICIA Y GINECOLOGIA}

La Sociedad Colombiana de Obstetricia y Ginecología está elaborando un volumen especial sobre las "Memorias de la Primera Convención". Dicha obra saldrá para fines de este año. Sobra recalcar el valor y trascendencia de esta publicación que no habrá de faltar en la biblioteca de ningún obstetra o ginecólogo colombiano. Contendrá todos los trabajos presentados en la Convención, de los cuales cabe mencionar los más importantes: un completo estudio de la esterilidad conyugal; un análisis de la toxemia gravídica y sus tratamientos; estatdística sobre la mortalidad materna en el embarazo $y$ modos de combatirla; utilidad de la radiopelvimetría; el problema del factor $R h$; el embríotomo de Turpin y otros varios artículos que serán de verdadero interés y utilidad no sólo para el especialista sino también para el médico general, que como en provincia, se ve en el caso de atender consultas de maternidad y ginecología.

Para informes y pedidos de estas "Memorias" favor dirigirse a las oficinas de la Sociedad Colombiana de Obstetricia y Ginecología en Bogotá, carrera 12, numero 20-69, oficina 309. 